\title{
Identification of a Predictive Biomarker for the Beneficial Effect of Keishibukuryogan, a Kampo (Japanese Traditional) Medicine, on Patients with Climacteric Syndrome
}

\author{
Takao Namiki, ${ }^{1}$ Hiromi Sato, ${ }^{2}$ Yukari Matsumoto, ${ }^{2}$ Haruka Kakikura, ${ }^{2}$ Koichi Ueno, ${ }^{2,3}$ \\ Atsushi Chino, ${ }^{4}$ Hideki Okamoto, ${ }^{1}$ Akito Hisanaga, ${ }^{1}$ Akiyo Kaneko, ${ }^{1}$ \\ Toshiaki Kita, ${ }^{1}$ Maki Kihara, ${ }^{5}$ Makio Shozu, ${ }^{5}$ and Katsutoshi Terasawa ${ }^{4}$ \\ ${ }^{1}$ Department of Japanese-Oriental (Kampo) Medicine, Graduate School of Medicine, Chiba University, Chiba 260-8670, Japan \\ ${ }^{2}$ Department of Geriatric Pharmacology and Therapeutics, Graduate School of Pharmaceutical Sciences, Chiba University, Chiba \\ 260-8670, Japan \\ ${ }^{3}$ Center for Preventive Medical Science, Chiba University, Chiba 260-0856, Japan \\ ${ }^{4}$ Chiba Chuo Medical Hospital, Chiba 264-0017, Japan \\ ${ }^{5}$ Department of Reproductive Medicine, Graduate School of Medicine, Chiba University, Chiba 260-8670, Japan
}

Correspondence should be addressed to Takao Namiki; tnamiki@faculty.chiba-u.jp

Received 17 May 2013; Revised 5 November 2013; Accepted 27 November 2013; Published 20 January 2014

Academic Editor: Gregory A. Plotnikoff

Copyright (C) 2014 Takao Namiki et al. This is an open access article distributed under the Creative Commons Attribution License, which permits unrestricted use, distribution, and reproduction in any medium, provided the original work is properly cited.

Keishibukuryogan (KBG; Guizhi-Fuling-Wan in Chinese) is one of the Kampo (Japanese traditional) medicines used to treat patients with climacteric syndrome. KBG can be used by patients who cannot undergo hormone replacement therapy due to a history of breast cancer. We evaluated whether cytosine-adenine (CA) repeat polymorphism of the estrogen receptor $\beta$ gene can be a predictor of the beneficial effect of KBG on climacteric syndrome. We also investigated the relationship between CA repeat polymorphism, the patients' profiles, and the therapeutic effect. We found that CA was an SS, SL, or LL genotype according to the number of repeats. We studied 39 consecutive patients with climacteric disorders who took KBG for 12 weeks. The diagnosis of climacteric disorders was made on the basis of the Kupperman index. KBG significantly improved the patients' climacteric symptoms (i.e., vasomotor symptoms in the patients with the LL genotype and melancholia in the patients with the SL genotype). No relationship between the patients' profiles and CA repeat polymorphism was recognized. CA repeat polymorphism could thus be a potential biomarker to predict the efficacy of KBG in climacteric syndrome, and its use will help to reduce the cost of treating this syndrome by focusing the administration of KBG on those most likely to benefit from it.

\section{Introduction}

Climacteric syndrome, which is caused by a decrease of the estrogen level during menopause, often severely impairs a woman's quality of life $[1,2]$. Many climacteric women suffer from vasomotor symptoms, mood disorders, vaginal dryness, headache, shoulder stiffness, and other problems. Hormone replacement therapy (HRT) is one of the most effective treatments for climacteric symptoms, especially for vasomotor symptoms, mood problems, and vaginal dryness. In recent years, however, epidemiological studies have reported adverse reactions to HRT such as an increase in the risks for stroke, deep vein thrombosis, dementia, and breast cancer [3-6]. In Japan, the use of Kampo medications (Japanese herbal medicine) is one alternative for controlling these symptoms in women who reject HRT or who cannot receive HRT due to a history of breast cancer [7].

Keishibukuryogan (KBG; Guizhi-Fuling-Wan in Chinese) is a Kampo medicine that has been effective in patients with climacteric syndrome. KBG consists of five crude drugs: cinnamon bark (Cinnamomum cassia Blume), peony root (Peonia lactiflora Palls), peach kernel (Prunus persica Batsch), 
poria sclerotium (Poria cocos Wolf), and moutan bark (Peonia suffruticosa Andrews). However, at present, the clinical evidence of KBG's efficacy is still limited because there have been few large-scale clinical trials. In addition, in a recent randomized study in the United States, patients with hot flashes did not show improvement as a result of KBG treatment, suggesting that the inclusion criteria of patients in clinical trials are important in showing the efficacy of Kampo medicine [8].

In 1996, the estrogen receptor (ER) $\beta$ gene was identified in an animal study [9]. Five isoforms of ER $\beta$ were subsequently confirmed in human ovarian tissue [10]. ER $\beta$ expression has also been observed in all types of granulose cells of the follicle [11], and polymorphisms of the ER $\beta$ gene are associated with abnormal ovulation [12]. The ER $\beta$ gene is suggested to play an important role in ovarian function. A retrospective study by our group revealed that the cytosine-adenine (CA) repeat polymorphism of the ER $\beta$ gene is correlated with climacteric symptoms [13]. In the present prospective study, therefore, we aimed to clarify the association between the CA repeat polymorphism of the ER $\beta$ gene and the therapeutic effects of KBG on women with climacteric symptoms. We evaluated whether the contribution of the CA repeat polymorphism of the $\operatorname{ER} \beta$ gene has a role in the effectiveness of KBG in women with climacteric syndrome.

\section{Subjects and Methods}

2.1. Subjects. The subjects were 39 consecutive females over 40 years old with climacteric symptoms at Chiba University Hospital and Chiba University's Kashiwanoha Clinic. Of these, 18 subjects were postmenopausal and the others were not yet menopausal. Menopause was diagnosed when the patient had not had a period in the past 12 months. The inclusion criterion of climacteric syndrome was a Kupperman index (KI) score over 20. The KI represents the total score of 11 components including vasomotor symptoms (hot flashes), paresthesia, insomnia, nervousness, melancholia, vertigo, concentration disorders, arthralgia or myalgia, headache, palpitations, and formication (a sensation of insects crawling over the skin). We simultaneously defined menopause via blood measurement as a follicle-stimulating hormone (FSH) level $\geq 40 \mathrm{mIU} / \mathrm{mL}$, as an estradiol $\left(\mathrm{E}_{2}\right)$ level $\leq 20 \mathrm{pg} / \mathrm{mL}$, or as an anti-Müllerian hormone $(\mathrm{AMH})$ of $<14.3 \mathrm{pmol} / \mathrm{L}$ as a reference of ovarian reserve. We excluded patients with physical diseases such as thyroid disease via blood examinations and psychiatric diseases such as depression via Self-rating Depression Scale (SDS) questionnaires.

2.2. Study Objective and Design. We investigated (1) the relationship between the CA repeat polymorphism and the KI before treatment with KBG and (2) the efficacy of KBG by comparing the total or component scores of the KI before and after treatment with KBG.

All patients took KBG extract granules at a dose of 2.5 grams (TJ-25, Tsumura Co., Tokyo) three times a day for 12 weeks. During the study, the patients came to our outpatient clinic every 4 weeks, and they underwent blood tests at the first visit and the final visit after the 12 week treatment was completed. The cessation or any change in the KBG treatment for any reason (including at the request of the patient) was considered dropping out of the study.

We explained the objectives of the study to each patient by asking her to fill out questionnaires (including Kupperman index, menstrual cycle, preset symptoms, and past history questionnaires) and obtained written informed consent from all patients. The study questionnaires were completed by patient interviewers.

We analyzed the correlation of each component of the KI with the detailed climacteric symptoms. We examined all patients for the CA repeat of the $\operatorname{ER} \beta$ gene. The number of $C A$ repeats was classified into two categories: $\leq 21$, defined as short (S), and $>21$, defined as long (L). We defined the three genotypes involving combinations of alleles as SS, SL, and LL.

This study was approved by the ethics committees of the Graduate School of Medicine, Chiba University, the Graduate School of Pharmaceutical Sciences, Chiba University, and the Chiba University Environment Field Science Center. In addition, as genetic information and personal medical information are critical to personal privacy, we managed all data very carefully with a stand-alone personal computer.

2.3. Analysis of CA Polymorphisms of the ER $\beta$ Gene. Genomic DNA was extracted from human peripheral blood leukocytes using the QIAamp DNA Mini Kit (Qiagen, Hilden, Germany) according to the manufacturer's protocol. Polymerase chain reaction (PCR) was performed in $75 \mu \mathrm{L}$ of reaction mixture with the following components: $150 \mathrm{ng}$ of human genomic DNA, oligonucleotide primers designed to amplify polymorphic CA repeats in intron 6 of the human ER $\beta$ gene (forward: $5^{\prime}$-CAA TTC CCA ATT CTA AGC CT- $3^{\prime}$ and reverse: $5^{\prime}$ ATT CTT CTT TAG GCC AGG CA-3') at $0.4 \mu \mathrm{M}$, dNTP mixture (TaKaRa Bio, Otsu, Japan) at $200 \mu \mathrm{M}, 7.5 \mu \mathrm{L}$ of $10 \times$ reaction buffer (containing $15 \mathrm{mM} \mathrm{MgSO}_{4}$ ) (Transgenomic, Omaha, NE), and $2.5 \mathrm{U}$ of optimase polymerase (Transgenomic). The reactions were brought to a total volume of $75 \mu \mathrm{L}$ by adding MilliQ water.

The amplification profiles were as follows: 35 cycles of denaturing at $94^{\circ} \mathrm{C}$ for $30 \mathrm{sec}$, annealing at $60^{\circ} \mathrm{C}$ for $30 \mathrm{sec}$, and extension at $72^{\circ} \mathrm{C}$ for $30 \mathrm{sec}$. The PCR products were purified with the QIAquick PCR Purification Kit (Qiagen) and used in the following analysis.

We conducted the analysis of the CA repeat polymorphisms by dye-terminator cycle sequencing using the Dye Terminator Cycle Sequencing Quick Start Kit (Beckman Coulter, Fullerton, CA) and the CEQ2000 DNA Analysis System (Beckman Coulter) according to the manufacturer's protocols.

2.4. Statistical Analysis. The statistical analysis was carried out as follows. The comparison of dispersibility between generations was done using the Bartlett test. Multiple comparisons were done using the Tukey-Kramer test in the case of equal dispersion or by the Steel-Dwass test in the case of nondispersion. The comparison of healthy subjects and 
TABLE 1: Clinical characteristics of the post- and premenopause patients.

\begin{tabular}{lccc}
\hline & All & Postmenopause & Premenopause \\
& $n=34$ & $n=17$ & $n=17$ \\
\hline Age & $49.5 \pm 4.69$ & $51.2 \pm 5.45$ & $47.7 \pm 3.02$ \\
Height $(\mathrm{cm})$ & $156.8 \pm 3.46$ & $155.6 \pm 3.44$ & $158.1 \pm 3.09$ \\
Body weight $(\mathrm{kg})$ & $52.7 \pm 6.67$ & $53.7 \pm 7.49$ & $51.7 \pm 5.78$ \\
BMI $\left(\mathrm{kg} / \mathrm{cm}^{2}\right.$ ) & $21.5 \pm 3.22$ & $22.3 \pm 3.75$ & $20.7 \pm 2.44$ \\
Age of menarche & $12.5 \pm 1.13$ & $12.2 \pm 0.81$ & $12.8 \pm 1.35$ \\
SDS & $46.2 \pm 8.51$ & $45.2 \pm 9.15$ & $47.2 \pm 7.98$ \\
Hysterectomized & 2 & 2 & 0.394 \\
Ratio of menopause (\%) & 44.1 & 88.2 & 0.278 \\
(delited hysterectomized) & & & 0.121 \\
\hline
\end{tabular}

Data are mean \pm SD. BMI: body mass index, SDS: self-rating depression scale. The $P$ values (post versus pre) were obtained by Student's $t$-test or Mann-Whitney test. ${ }^{*} P<0.05$.

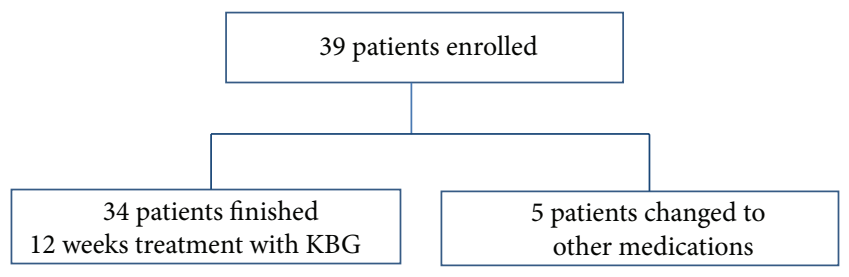

FIGURE 1: Flow chart of patients enrolled in the study.

patients with climacteric disorders exhibiting dispersibility was done by $F$-test and analyzed using Student's $t$-test in the case of equal dispersion or Welch's $t$-test in the case of nondispersion. The coefficient of correlation was obtained by Pearson's correlation test using PASW Statistics 18. The sensitivity, specificity, and the distribution of frequencies were calculated using cross-tabulation with PASW Statistics 18. StatLight 1997 software (Yukms, Tokyo) was used for the statistical analyses. $P$ values $<0.05$ were accepted as significant in all analyses.

\section{Results}

3.1. Characteristics of the Subjects Enrolled in This Study. Five of the 39 subjects dropped out; the remaining 34 patients with climacteric symptoms all took the KBG for 12-weeks (Figure 1). The postmenopause and premenopause groups were each 17 subjects. There were no significant differences between these groups except in age and height (Table 1). The past histories of 11 subjects showed myoma uterus or endometriosis. Two subjects had the history of hysterectomized. No serious adverse reaction to KBG was observed.

3.2. Relationship between Subjects' Profiles and CA Genotype. We classified the 34 patients into three genotypes: 9 patients as SS, 12 as SL, and 13 as LL. We compared the patients' total $\mathrm{KI}$ scores before treatment according to the CA genotype, and we found no significant differences in the patients' profiles

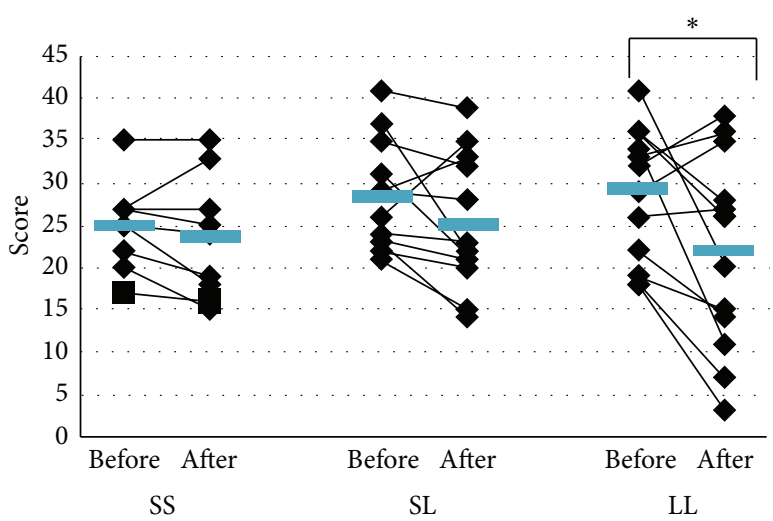

FIGURE 2: Changes in the subjects' Kupperman index (KI) from before KBG treatment to after the treatment were compared with each of the three genotypes of the CA repeat polymorphism of the ER $\beta$ gene. Transverse bars indicate averages. $P$ values (before versus after) were obtained by paired $t$-test. ${ }^{*} P<0.05$.

among the genotypes (Table 2). There were no significant differences among the three genotype groups except for the FSH level in the LL genotype (Table 3). The high FSH and low $\mathrm{E}_{2}$ levels indicated that those subjects were in perimenopause.

3.3. Correlation between KBG's Clinical Efficacy and CA Genotypes. To examine the effectiveness of KBG in patients with climacteric symptoms, we compared the changes in the patients' KI before and after treatment in each CA genotype. Regarding the total KI score, a significant improvement was observed only in the LL group (Figure 2). Likewise, we evaluated the improvement in the 11 climacteric symptoms included in the KI. The patients with the LL genotype showed significant improvement in climacteric KI components such as vasomotor symptoms, and patients with the SL genotype showed a significant beneficial effect on melancholia following the KBG treatment (Table 4). 
TABLE 2: Clinical characteristics of 34 patients who finished the KBG treatment, classified by their CA repeat polymorphism of the ER $\beta$ gene.

\begin{tabular}{|c|c|c|c|c|}
\hline & $\begin{array}{c}\text { SS } \\
n=9\end{array}$ & $\begin{array}{c}\text { SL } \\
n=12\end{array}$ & $\begin{array}{c}\text { LL } \\
n=13\end{array}$ & $P$ \\
\hline Age & $50.1 \pm 2.37$ & $51.2 \pm 5.29$ & $47.5 \pm 4.86$ & 0.100 \\
\hline Height $(\mathrm{cm})$ & $157.1 \pm 3.78$ & $155.6 \pm 3.22$ & $157.7 \pm 3.39$ & 0.502 \\
\hline Body weight (kg) & $54.0 \pm 8.26$ & $53.3 \pm 6.26$ & $51.2 \pm 6.07$ & 0.913 \\
\hline BMI $\left(\mathrm{kg} / \mathrm{cm}^{2}\right)$ & $22.0 \pm 4.18$ & $22.1 \pm 3.21$ & $20.6 \pm 2.43$ & 0.747 \\
\hline Age of menarche & $12.6 \pm 1.33$ & $12.3 \pm 1.07$ & $12.5 \pm 1.13$ & 0.901 \\
\hline SDS & $46.8 \pm 10.29$ & $46.0 \pm 9.05$ & $45.9 \pm 7.30$ & 0.971 \\
\hline KI & $25.0 \pm 5.12$ & $28.4 \pm 6.49$ & $29.2 \pm 7.85$ & 0.341 \\
\hline Hysterectomized & 0 & 1 & 1 & \\
\hline $\begin{array}{l}\text { Ratio of menopause (\%) } \\
\text { (delited hysterectomized) }\end{array}$ & 33.3 & 66.7 & 30.8 & \\
\hline
\end{tabular}

Data are mean \pm SD. S: short allele, L: long allele, SDS: self-rating depression scale, and KI: Kupperman index. $P$ values (SS versus SL versus LL) were obtained by Kruskal-Wallis test or 1-way ANOVA.

TABLE 3: The patients' hormone levels before and after treatment compared by CA repeat polymorphism of the ER $\beta$ gene.

\begin{tabular}{lccc}
\hline & SS & SL & LL \\
& $n=9$ & $n=12$ & $n=13$ \\
\hline $\mathrm{E}_{2}(\mathrm{pg} / \mathrm{mL})$ & & & \\
$\quad$ Before & $69.2 \pm 103.9$ & $65.2 \pm 89.5$ & $104.6 \pm 142.8$ \\
$\quad$ After & $59.0 \pm 97.3$ & $32.0 \pm 41.6$ & $78.3 \pm 100.9$ \\
FSH (mIU/mL) & & & 0.305 \\
$\quad$ Before & $49.0 \pm 29.0$ & $53.4 \pm 27.2$ & $24.1 \pm 29.3$ \\
After & $39.1 \pm 21.7$ & $55.1 \pm 29.5$ & $25.5 \pm 26.7$ \\
AMH (pmol/L) & & & $0.044^{\#}$ \\
Before & $1.33 \pm 1.03$ & $1.12 \pm 1.22$ & 0.051 \\
After & $1.11 \pm 1.22$ & $0.90 \pm 0.48$ & $4.42 \pm 4.83$ \\
\hline
\end{tabular}

Data are mean \pm SD. S: short allele, L: long allele. $P$ values (SS versus SL versus LL) were obtained by Kruskal-Wallis test or 1-way ANOVA. ${ }^{\#} P<0.05$.

\section{Discussion}

We determined the $\mathrm{CA}$ repeat polymorphism of the $\mathrm{ER} \beta$ gene in 34 climacteric patients and investigated the relationships of the CA genotypes with the patients' backgrounds and the therapeutic effects of KBG. The results suggested that KBG was effective in climacteric patients who had either the LL or SL genotype. The serum estrogen levels in the LL genotype patients, which were higher than those in the other two genotype groups, might partially explain the efficacy of KGB; although the KI values in the LL group were higher than those in the SS group.

The use of KBG for patients with climacteric syndrome can be very beneficial because KBG has no contraindications except in patients with an allergy to KBG. Because KBG has no direct effect on increasing estrogen levels, it can also be used for patients with climacteric syndrome who have a history of breast or ovarian cancer, both of which are contraindications for HRT.

In ERs, many genetic polymorphisms including singlenucleotide polymorphisms (SNPs) and a microsatellite polymorphism have been reported. In 1998, Tsukamoto et al. first characterized the CA repeat polymorphism (D14S1026) of the $\operatorname{ER} \beta$ gene in a Japanese population [14]. A systematic mutation screening subsequently detected five different sequence variants, including two mutations and three polymorphisms [15]. Importantly, in an in vitro functional analysis, the presence of the valine in position 320 showed significantly decreased maximal transcriptional activity [16]. The number of CA repeats ranges from 13 to 30 .

The correlation of the CA repeat polymorphism with various diseases has been reported in breast cancer [17], endometrial cancer [18], osteoporosis [19], and Alzheimer's disease [20]. A relationship between the CA repeat polymorphism and the androgen concentration [21] and prolactin levels [22] has also been reported, which strongly suggests that the CA repeat polymorphism is related to the secretion of sexual hormones. The distribution of the number of repeats of CA exhibits racial differences; there is a single peak of the specific CA repeat number in Japan and China [19, 23], while a bimodal distribution has been shown in Caucasians and in India $[18,24]$. The racial differences in the distribution of the CA repeat polymorphism may explain why there have been no significant results of clinical trials in the United States. 
TABLE 4: Comparison of Kupperman index components before and after 12 weeks' treatment by genotypes of the CA repeat polymorphism of the $\operatorname{ER} \beta$ gene.

\begin{tabular}{|c|c|c|c|c|}
\hline & $\begin{array}{c}\text { SS } \\
n=9\end{array}$ & $\begin{array}{c}\text { SL } \\
n=12\end{array}$ & $\begin{array}{c}\text { LL } \\
n=13\end{array}$ & $P$ \\
\hline \multicolumn{5}{|c|}{ Vasomotor } \\
\hline Before & $9.78 \pm 2.11$ & $10.67 \pm 1.97$ & $10.46 \pm 2.03$ & 0.583 \\
\hline After & $9.33 \pm 2.00$ & $10.00 \pm 2.70$ & $7.08 \pm 4.05^{*}$ & 0.116 \\
\hline \multicolumn{5}{|c|}{ Paresthesia } \\
\hline Before & $1.33 \pm 1.73$ & $1.33 \pm 1.56$ & $2.00 \pm 1.83$ & 0.563 \\
\hline After & $1.33 \pm 1.41$ & $1.33 \pm 1.30$ & $1.38 \pm 2.06$ & 0.904 \\
\hline \multicolumn{5}{|l|}{ Insomnia } \\
\hline Before & $3.11 \pm 1.76$ & $2.83 \pm 2.17$ & $2.77 \pm 2.65$ & 0.933 \\
\hline After & $2.44 \pm 1.67$ & $2.33 \pm 2.23$ & $2.15 \pm 2.38$ & 0.884 \\
\hline \multicolumn{5}{|c|}{ Nervousness } \\
\hline Before & $3.11 \pm 1.76$ & $3.33 \pm 1.56$ & $3.69 \pm 1.97$ & 0.747 \\
\hline After & $3.11 \pm 2.26$ & $3.00 \pm 1.60$ & $2.92 \pm 1.93$ & 0.973 \\
\hline \multicolumn{5}{|c|}{ Melancholia } \\
\hline Before & $1.78 \pm 0.97$ & $1.92 \pm 0.90$ & $1.69 \pm 1.18$ & 0.916 \\
\hline After & $1.56 \pm 0.88$ & $1.25 \pm 0.75^{*}$ & $1.38 \pm 1.19$ & 0.711 \\
\hline \multicolumn{5}{|l|}{ Vertigo } \\
\hline Before & $0.78 \pm 0.67$ & $1.00 \pm 0.95$ & $0.92 \pm 0.86$ & 0.866 \\
\hline After & $1.00 \pm 0.87$ & $0.83 \pm 0.83$ & $0.69 \pm 1.03$ & 0.590 \\
\hline \multicolumn{5}{|c|}{ Concentration disorders } \\
\hline Before & $1.67 \pm 0.87$ & $2.08 \pm 0.67$ & $2.23 \pm 1.01$ & 0.246 \\
\hline After & $1.56 \pm 0.88$ & $2.00 \pm 0.60$ & $1.92 \pm 1.04$ & 0.491 \\
\hline \multicolumn{5}{|c|}{ Arthralgia or myalgia } \\
\hline Before & $1.67 \pm 0.87$ & $2.00 \pm 0.95$ & $2.23 \pm 1.01$ & 0.285 \\
\hline After & $1.56 \pm 0.53$ & $2.00 \pm 0.95$ & $1.92 \pm 1.04$ & 0.397 \\
\hline \multicolumn{5}{|l|}{ Headache } \\
\hline Before & $0.78 \pm 0.83$ & $1.75 \pm 1.06$ & $1.77 \pm 1.17$ & 0.068 \\
\hline After & $0.67 \pm 0.87$ & $1.42 \pm 1.24$ & $1.31 \pm 1.11$ & 0.281 \\
\hline \multicolumn{5}{|c|}{ Palpitations } \\
\hline Before & $1.00 \pm 1.00$ & $0.92 \pm 1.00$ & $1.08 \pm 1.12$ & 0.947 \\
\hline After & $0.89 \pm 0.78$ & $0.75 \pm 0.62$ & $0.69 \pm 0.75$ & 0.808 \\
\hline \multicolumn{5}{|c|}{ Formication } \\
\hline Before & $0.00 \pm 0.00$ & $0.58 \pm 1.00$ & $0.38 \pm 0.87$ & 0.177 \\
\hline After & $0.11 \pm 0.33$ & $0.33 \pm 0.49$ & $0.54 \pm 0.78$ & 0.322 \\
\hline
\end{tabular}

Data are mean \pm SD. $P$ values (SS versus SL versus LL) were obtained by Kruskal-Wallis test. $P$ values (before versus after) were obtained by Signed-Wilcoxon test. ${ }^{*} P<0.05$.

In our previous study, women with the SS genotype were shown to have an increased risk of perimenopausal symptoms and menopause-related psychological and vasomotor symptoms, and they required HRT to control their severe climacteric symptoms. It has been reported that most patients with the SS genotype show strong vasomotor symptoms, and HRT would likely be used to treat them $[13,25]$. $\mathrm{ER} \beta$ genotypes might relate to the severity of vasomotor symptoms in climacteric syndrome. In the present study, the KBG treatment had no significant effect on vasomotor symptoms in the SS genotype group but it was effective against these symptoms in the LL genotype group. Although our LL patients had high KI scores, vasomotor symptoms were improved in the LL group. This result is related to the "Sho" diagnosis in Kampo medicine ("Sho" diagnosis is diagnostic steps to determine Kampo medicines).

The mechanism of vasomotor symptoms in patients with climacteric syndrome remains unclear. One mechanism that has been reported is the increase of the calcitonin gene-related peptide (CGRP) concentration, which has the effect of microvascular dilation [26], and another is the lowering of blood sex hormone-binding globulin (SHBG) levels due to a decreased blood estradiol concentration [27]. However, it was reported that premenopausal patients with 
a relatively short CA repeat of the ER $\beta$ gene had higher serum levels of SHBG compared to those with a longer repeat region [21].

Westberg et al. reported that their patients with short CA repeat had higher SBGH levels which might be derived from higher androgen (testosterone) levels, although there was no correlation between E2 levels and genotype [21]. They also checked the relationship between prolactin levels and CA repeats, and they observed a significant difference in prolactin levels: their "SS + SL" group had significantly higher prolactin levels compared to the "LL" group, but there was no such correlation for estradiol and prolactin in any of the subgroups with respect to $\mathrm{ER} \beta$ [22]. It remains unknown whether ER $\beta$ polymorphism has any effect on the SHBG level.

The release of hormones may be affected by the menstrual period. Westberg et al. [21] noted that serum samples are obtained in the follicular phase when the levels of estradiol are relatively low, although doing so is difficult in clinical practice. However, Comings proposed that even though the CA repeat region in the ER $\beta$ is situated in a nontranslated region, there are several mechanisms that might explain such a relationship between short repeats in nontranslated regions and gene function, including their potential to form alternative DNA structures (such as Z-DNA) that modulate transcriptional activity [28].

Regarding the mechanism of KBG as a treatment for vasomotor symptoms, it has been reported that the increase in skin temperature is inhibited by the normalization of the high estrogen-independent sensitivity of the CGRP receptor $[29,30]$. KBG shows estrogen-like activity [31]. In addition, because KBG shows an agonistic activity for ER $\beta$, KBG has been suggested to act through $\operatorname{ER} \beta$ [32]. In order to clarify the relationship between CGRP and vasomotor symptoms, measurements of the CGRF level are needed to determine the concentration of CGRF in each genotype. However, it is difficult to detect the peak concentration of CGRP because it occurs during vasomotor symptoms $[33,34]$.

In the melancholia related to climacteric syndrome, a significant improvement was shown in only the SL genotype patients in the present study. However, the trend in the KI melancholia score before and after KBG treatment was almost the same in all three genotype groups. Kanda et al. reported that Kampo medication can be more effective for the melancholia related to climacteric syndrome than HRT [35]. They reported that melancholia improved in 58\% of the patients treated with Kampo medication (KBG was administrated on $25 \%$ of the patients) whereas in $33.3 \%$ of the patients treated with HRT. Kampo medication might have different effects with HRT on patients with climacteric syndrome.

In Japan, more than $80 \%$ of medical doctors prescribe Kampo medicine [7, 36]. Kampo formulae are regulated as prescription pharmaceutical drugs by the Japanese Ministry of Health and have been covered by the national health insurance for about 30 years. By using the theory of Kampo medicine, Kampo specialists analyze a patient's constitution and various complaints and then prescribe various types of
Kampo medicine. Making a Kampo diagnosis is relatively difficult for nonspecialist doctors, and thus treating climacteric patients with Kampo medicines is also difficult. Analyzing the CA genotype may therefore help Kampo expert doctors as well as nonexpert doctors to choose an appropriate Kampo prescription.

With these results, we have taken the first step in using the ER $\beta$ genotype as a predictive biomarker for the beneficial effects of KBG on patients with climacteric syndrome. A major limitation of our study was its small sample size $(n=$ 39). The sample sizes for each of the three genotypes (SS, SL, and LL) were necessarily even smaller, and this may have affected our ability to determine significant differences between groups. Nevertheless, our study indicates that the ER $\beta$ genotype can be expected to eventually be a useful biomarker as a predictor of the efficacy of KBG. Evidence relevant to the CA polymorphism should be collected through larger-scale and more detailed studies.

\section{Conflict of Interests}

Takao Namiki, Hideki Okamoto, and Akito Hisanaga got a grant as Research Support from Tsumua CO. Hiromi Sato, Yukari Matsumoto, Haruka Kakikura, Ueno Koichi, Atsushi Chino, Akiyo Kaneko, Toshiaki Kita, Maki Kihara, Makio Shozu, and Katsutoshi Terasawa have no conflict of interests regarding the publication of this paper.

\section{Acknowledgments}

This work was supported by a research grant from the Ministry of Health, Labour and Welfare, Japan. The authors would like to thank Hana Sugai, Ayano Ito, and Atsushi Yanagibori for their help. The Department of Japanese-Oriental (Kampo) Medicine, Graduate School of Medicine, Chiba University, was supported by a grant from Tsumura CO.

\section{References}

[1] L. Speroff and M. A. Fritz, Clinical Gynecologic Endocrinology and Infertility, vol. 7, Lippincott Williams \& Wilkins, Philadelphia, Pa, USA, 2005.

[2] NIH State-of-the-Science Panel, "National Institutes of Health State-of-the-Science conference statement: management of menopause-related symptoms," Annals of Internal Medicine, vol. 142, no. 12, pp. 1003-1013, 2005.

[3] J. E. Rossouw, G. L. Anderson, R. L. Prentice et al., "Risks and benefits of estrogen plus progestin in healthy postmenopausal women: principal results from the women's health initiative randomized controlled trial," The Journal of the American Medical Association, vol. 288, no. 3, pp. 321-333, 2002.

[4] S. A. Shumaker, C. Legault, S. R. Rapp et al., "Estrogen plus progestin and the incidence of dementia and mild cognitive impairment in postmenopausal women: the women's health initiative memory study: a randomized controlled trial," The Journal of the American Medical Association, vol. 289, no. 20, pp. 2651-2662, 2003.

[5] R. T. Chlebowski, S. L. Hendrix, R. D. Langer et al., "Influence of estrogen plus progestin on breast cancer and mammography in 
healthy postmenopausal women: the women's health initiative randomized trial," The Journal of the American Medical Association, vol. 289, no. 24, pp. 3243-3253, 2003.

[6] V. Beral, "Breast cancer and hormone-replacement therapy in the Million Women Study," The Lancet, vol. 362, no. 9382, pp. 419-427, 2003.

[7] A. Ishibashi, H. Kosoto, S. Ohno et al., "General introduction to Kampo," in Introduction to Kampo, Japanese Traditional Medicine, The Japanese Society of Oriental Medicine, pp. 2-13, Elsevier, Tokyo, Japan, 2005.

[8] G. A. Plotnikoff, K. Watanabe, C. Torkelson, J. La Valleur, and D. M. Radosevich, "The TU-025 keishibukuryogan clinical trial for hot flash management in postmenopausal women: results and lessons for future research," Menopause, vol. 18, no. 8, pp. 886-892, 2011.

[9] G. G. Kuiper, E. Enmark, M. Pelto-Huikko, S. Nilsson, and J.-A. Gustafsson, "Cloning of a novel estrogen receptor expressed in rat prostate and ovary," Proceedings of the National Academy of Sciences of the United States of America, vol. 93, no. 12, pp. 59255930, 1996.

[10] J. T. Moore, D. D. McKee, K. Slentz-Kesler et al., "Cloning and characterization of human estrogen receptor $\beta$ isoforms," Biochemical and Biophysical Research Communications, vol. 247, no. 1, pp. 75-78, 1998.

[11] P. T. Saunders, M. R. Millar, K. Williams et al., "Differential expression of estrogen receptor- $\alpha$ and $-\beta$ and androgen receptor in the ovaries of marmosets and humans," Biology of Reproduction, vol. 63, no. 4, pp. 1098-1105, 2000.

[12] C. Sundarrajan, W. X. Liao, A. C. Roy, and S. C. Ng, "Association between estrogen receptor- $\beta$ gene polymorphisms and ovulatory dysfunctions in patients with menstrual disorders," The Journal of Clinical Endocrinology and Metabolism, vol. 86, no. 1, pp. 135-139, 2001.

[13] C. Takeo, E. Negishi, A. Nakajima et al., "Association of cytosine-adenine repeat polymorphism of the estrogen receptor- $\beta$ gene with menopausal symptoms," Gender Medicine, vol. 2, no. 2, pp. 96-105, 2005.

[14] K. Tsukamoto, S. Inoue, T. Hosoi, H. Orimo, and M. Emi, "Isolation and radiation hybrid mapping of dinucleotide repeat polymorphism at the human estrogen receptor $\beta$ locus," Journal of Human Genetics, vol. 43, no. 1, pp. 73-74, 1998.

[15] K. Rosenkranz, A. Hinney, A. Ziegler et al., "Systematic mutation screening of the estrogen receptor beta gene in probands of different weight extremes: identification of several genetic variants," The Journal of Clinical Endocrinology \& Metabolism, vol. 83, no. 12, pp. 4524-4527, 1998.

[16] C. Zhao, L. Xu, M. Otsuki et al., "Identification of a functional variant of estrogen receptor beta in an African population," Carcinogenesis, vol. 25, no. 11, pp. 2067-2073, 2004.

[17] A. Tsezou, M. Tzetis, C. Gennatas et al., "Association of repeat polymorphisms in the estrogen receptors alpha, beta (ESR1, ESR2) and androgen receptor (AR) genes with the occurrence of breast cancer," The Breast, vol. 17, no. 2, pp. 159-166, 2008.

[18] V. W. Setiawan, S. E.Hankinson, G. A.Colditz, D. J.Hunter, and I. D. Vivo, "Estrogen receptor $\beta$ (ESR2) polymorphisms and endometrial cancer (United States)," Cancer Causes \& Control, vol. 15, no. 6, pp. 627-633, 2004.

[19] S. Ogawa, T. Hosoi, M. Shiraki et al., "Association of estrogen receptor $\beta$ gene polymorphism with bone mineral density," Biochemical and Biophysical Research Communications, vol. 269, no. 2, pp. 537-541, 2000.
[20] C. Forsell, E. Enmark, K. Axelman et al., "Investigations of a CA repeat in the oestrogen receptor $\beta$ gene in patients with Alzheimer's disease," European Journal of Human Genetics, vol. 9, no. 10, pp. 802-804, 2001.

[21] L. Westberg, F. Baghaei, R. Rosmond et al., "Polymorphisms of the androgen receptor gene and the estrogen receptor $\beta$ gene are associated with androgen levels in women," The Journal of Clinical Endocrinology and Metabolism, vol. 86, no. 6, pp. 25622568, 2001.

[22] L. Westberg, H.-P. Ho, F. Baghaei et al., "Polymorphisms in oestrogen and progesterone receptor genes: possible influence on prolactin levels in women," Clinical Endocrinology, vol. 61, no. 2, pp. 216-223, 2004.

[23] H. H. L. Lau, A. Y. Y. Ho, K. D. K. Luk, and A. W. C. Kung, "Estrogen receptor $\beta$ gene polymorphisms are associated with higher bone mineral density in premenopausal, but not postmenopausal southern Chinese women," Bone, vol. 31, no. 2, pp. 276-281, 2002.

[24] A. Khattri, R. K. Pandey, N. J. Gupta et al., "CA repeat and RsaI polymorphisms in ER $\beta$ gene are not associated with infertility in Indian men," International Journal of Andrology, vol. 32, no. 1, pp. 81-87, 2009.

[25] C. Takeo, K. Ugai, J. Araki et al., "Pharmacogenetics of hormone replacement therapy for climacteric symptoms," Biochemical and Biophysical Research Communications, vol. 374, no. 4, pp. 604-608, 2008.

[26] J.-T. Chen, Y. Hirai, Y. Seimiya, K. Hasumi, and M. Shiraki, "Menopausal flushes and calcitonin-gene-related peptide," The Lancet, vol. 342, no. 8862, 49 pages, 1993.

[27] H. G. Burger, E. C. Dudley, J. Cui, L. Dennerstein, and J. L. Hopper, "A prospective longitudinal study of serum testosterone, dehydroepiandrosterone sulfate, and sex hormonebinding globulin levels through the menopause transition," The Journal of Clinical Endocrinology and Metabolism, vol. 85, no. 8, pp. 2832-2838, 2000.

[28] D. E. Comings, "Polygenic inheritance and micro/minisatellites," Molecular Psychiatry, vol. 3, no. 1, pp. 21-31, 1998.

[29] M. Noguchi, Y. Ikarashi, M. Yuzurihara et al., "Skin temperature rise induced by calcitonin gene-related peptide in gonadotropin-releasing hormone analogue-treated female rats and alleviation by Keishi-bukuryo-gan, a Japanese herbal medicine," Life Sciences, vol. 76, no. 18, pp. 2079-2090, 2005.

[30] M. Noguchi, Y. Ikarashi, M. Yuzurihara et al., "Effects of the Japanese herbal medicine Keishi-bukuryo-gan and $17 \beta$ estradiol on calcitonin gene-related peptide-induced elevation of skin temperature in ovariectomized rats," Journal of Endocrinology, vol. 176, no. 3, pp. 359-366, 2003.

[31] Y. Kumagai, S. Hyuga, M. Hyuga, K. Watanabe, T. Kawanishi, and T. Hanawa, "Estrogen-like activity in Kampo medicines used for menopausal symptoms and gynecological diseases," Journal of Traditional Medicines, vol. 22, no. 4, pp. 228-236, 2005.

[32] K. Watanabe, S. Hyuga, M. Hyuga, T. Kawanishi, and T. Hanawa, "Agonistic or antagonistic action of kampo medicines used for menopausal symptoms on estrogen receptor subtypes, Era and Herb," Journal of Traditional Medicines, vol. 23, no. 6, pp. 203-207, 2006.

[33] J.-T. Chen, Y. Hirai, Y. Seimiya, K. Hasumi, and M. Shiraki, "Menopausal flushes and calcitonin-gene-related peptide," The Lancet, vol. 342, no. 8862, 49 pages, 1993. 
[34] J.-T. Chen and M. Shiraki, "Menopausal hot flash and calciotonin gene-related peptide; effect of Keishi-bukuryo-gan, a kampo medicine, related to plasma calciotonin gene-related peptide level," Maturitas, vol. 45, no. 3, pp. 199-204, 2003.

[35] I. Kanda, S. Nemoto, Y. Kajiwara, H. Kurokawa, H. Takeda, and H. Hata, "Kampo treatment for climacteric syndrome: a comparison with HRT by climacteric symptoms," Progress of Obstetrics and Gynecology in Kampo Research, no. 21, pp. 35-39, 2004 (Japanese).

[36] E. C. Moschik, C. Mercado, T. Yoshino, K. Matsuura, and K. Watanabe, "Usage and attitudes of physicians in Japan concerning traditional Japanese medicine (kampo medicine): a descriptive evaluation of a representative questionnairebased survey," Evidence-Based Complementary and Alternative Medicine, vol. 2012, Article ID 139818, 13 pages, 2012. 


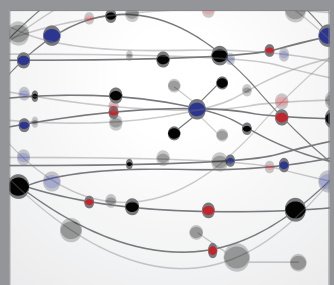

The Scientific World Journal
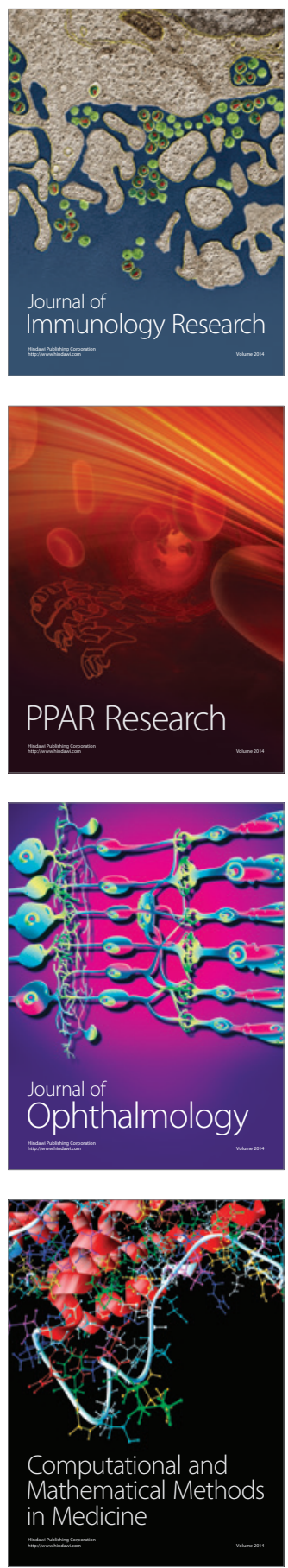

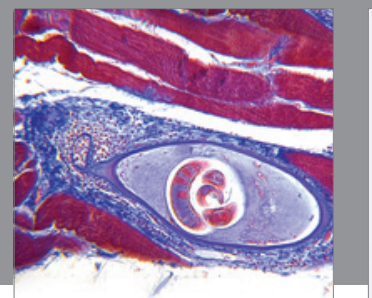

Gastroenterology

Research and Practice
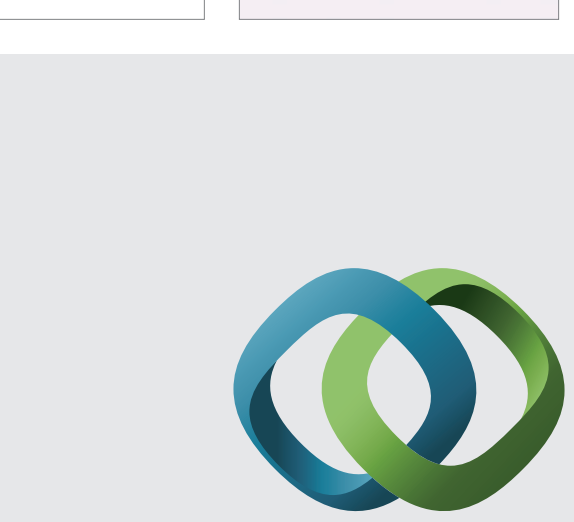

\section{Hindawi}

Submit your manuscripts at

http://www.hindawi.com
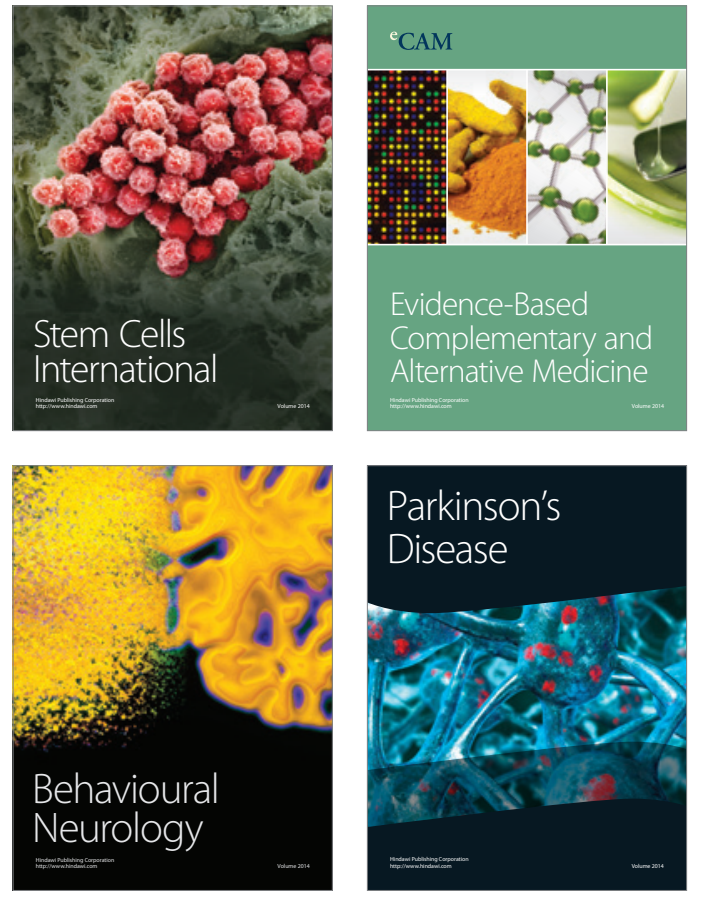
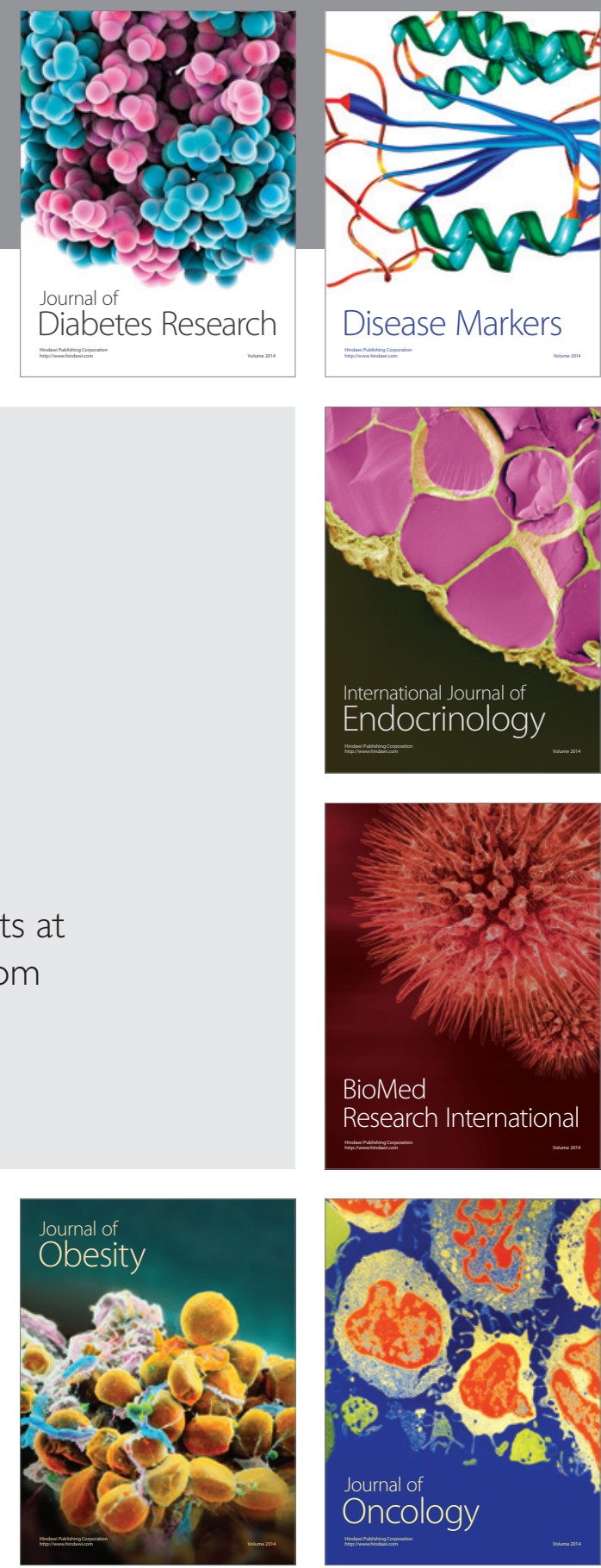

Disease Markers
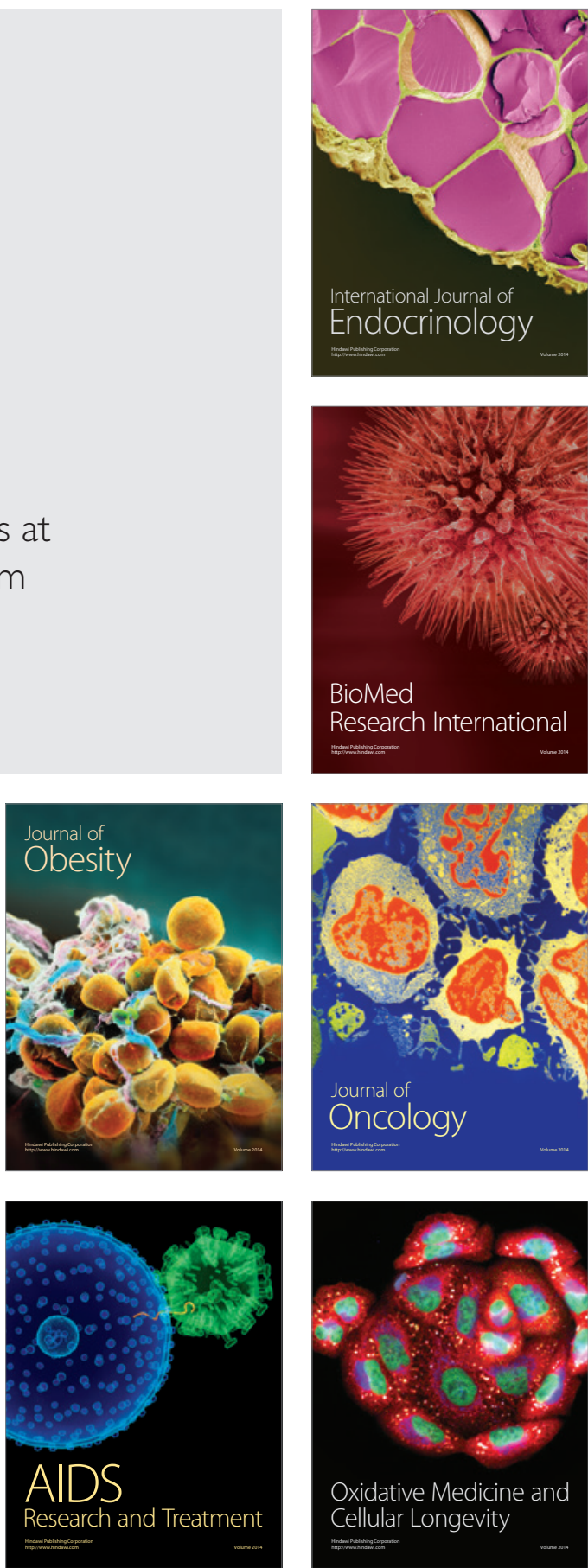